\title{
JCEIB
}

Open Access; Volume 1 pp. 29-41; March2017

(C) Universiti Malaysia Pahang Publisher

DOI: https://doi.org/10.15282/JCEIB-V1-05.31/3/2017/1.1.1

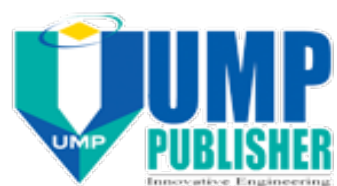

\section{INVESTIGATION OF BIOPLASTIC PROPERTIES DEVELOPED FROM ACRYLATE EPOXIDIZED SOYBEAN OIL THROUGH RING OPENING POLYMERIZATION PROCESS}

\author{
Hiew Ming $\mathrm{Yu}^{\mathrm{a}}$, Arun Gupta ${ }^{1 \mathrm{a} *}$, Ritu Gupta ${ }^{\mathrm{b}}$ and Muhamed Saad Bala Husain ${ }^{\mathrm{a}}$ \\ ${ }^{a}$ Faculty of Chemical \& Natural Resources Engineering,University Malaysia Pahang, Gambang 26300, \\ Pahang, Malaysia \\ ${ }^{\mathrm{b}}$ IBM Centre of Excellence, University Malaysia Pahang, Gambang 26300, Pahang, Malaysia \\ * Corresponding author: E-mail: arun@ump.edu.my \\ Tel.: +6095492867
}

\begin{abstract}
Soybean oil is one of the major vegetable oils containing more than $99 \%$ of triglycerides of saturated and unsaturated fatty acids and has become an interesting source to produce bioplastic. This study investigates the synthesis and characterization of bioplastic developed by the acrylate epoxidized soybean oil through ring opening polymerization process. The mechanical properties of the samples were characterized using Fourier Transform Infrared Spectroscopy, Thermogravimetric analysis and the physio-chemical properties of the bioplastics were studied. In this study, the bioplastic made up from soybean oil with the lowest glycerol concentration showed the best mechanical properties.
\end{abstract}

Keywords: Bioplastic, Acrylate epoxidized soybean oil, Biodegradable

\subsection{INTRODUCTION}

Plastics is one of the most highly valued materials mainly because they play an important role in human life such as food packaging and biomedical applications Piringer \& Baner (2008) and Raheem(2012). The development of plastics is believed to have started around 1860 with an intention of developing (Browne, 1993) a new substitute for natural ivory. In addition, plastics have been one of the most highly valued materials mainly because of their extraordinary versatility and low cost (Murray, 2007). Plastics are everywhere in human's life such as packaging, constructions and biomedical applications. Plastics are cheap with its wide ranges of usage yet it caused a huge environmental problem, because they do not degrade in landfills and cannot be composted (Hopewell et.al, 2009). Conventional plastics made of petroleum and its aliened components have caused the depletion of natural resources and environmental issues as it does not degrade in landfill (Hopewell, et al 2009). Most of the conventional plastics are made from polyolefins such as poly (propylene) (PP), poly (carbonate) (PC), poly (vinyl chloride) (PVC), poly (ethylene) (PE), poly (styrene) (PS) etc. These conventional plastics are made of petroleum and its allied components, these natural resources take millions of years to form and are finite in quantity. In addition, plastics derived from fossil resources are largely non-biodegradable. Thus, the depletion of petroleum resources and increasing environmental awareness and regulations have triggered for the development of next generation materials that are environment-friendly and available resourcefully to meet the increasing demand for plastics (Muniyappa et al, 1996). In addition, as a result of 
advancing technology a lot of problems and damage has been done to the environment over the years, which has now become a huge concern. This threat to the ecosystem is extremely big due to which manufacturing industries, especially the packaging, construction, and automobile industries, are, searching for new environmentally friendly biodegradable substitutes that can successfully replace their conventional synthetic nonbiodegradable counterparts. One way to reduce the use of fully petroleum based plastic products, is to substitute the synthetic fibres to natural wood and agriculture fibres. Researchers have been conducting research on composites made from wood fibers, plastics and recycled plastics as well as hybrid composites. (Clemons 2002,. Ashori, 2008,. Rivai et al 2014). These kinds of composites have been found to exhibit improved properties such as mechanical, thermal, and morphological properties yet they are not fully bio based (Islam et al 2014,. Islam et al 2016). Hence, a lot of attention is now being paid on preparation and application of bio-based polymers because of environmental concerns (Mohanty \& Misra (2002), Gandini(2008) and Raquez et al (2010).

Development of bioplastics which are made from renewable resources and biodegradable materials can reduce the depleting fossil fuels and environment impact. Bioplastics made from renewable resources are biobased, biodegradable or both. Biobased means the material or the product is partly derived from biomass (plants) while biodegradable means the materials can be converted into natural substances such as water and carbon dioxide by the chemical process of the micro-organisms in the environment. Today, bioplastics play an important role in various industry applications such as food packaging and composting bags. Vegetable oils are highly suitable starting materials for polymers due to their abundance, low cost, biodegradability, environmental benefits and variety of functional groups. They are triglycerides with different composition of fatty acids depending on the plant, crop, season, growing conditions and purification methods (Kim \& Sharma, 2012). Some of the most commonly used vegetable oils to synthesis bioplastics included castor oil, palm oil, and sunflower oil. Triglyceride-based vegetable oils, such as soybean, jatropha, linseed, sunflower, palm, castor, nahar seed, and canola oil, are being considered as precursors in the production of polymers. Soybean oil is one of the major vegetable oils containing more than $99 \%$ of triglycerides of saturated and unsaturated fatty acids.

Soybean oil is available abundantly across the world and is the second largest crop in the United States of America. In addition, the unsaturated sites in soybean oil can be used to introduce new functional groups like epoxides. Epoxidised soybean oil can be used as a stabilizer and plasticizer in the polymers or as an additive in lubricants and can also be converted into polyols by ring opening of the oxirane groups, resulting in intermediates that are used in polyurethane (Kiatsimkul, 2008). Its sustainability, low price and ease of manufacture make this bio resin an attractive alternative to petroleum-based plastics. One of the problems of bioplastics made from trigriceride-based materials is that they exhibit low rigidity and strength, which limit their use for practical applications (Khot et al, 2001). To improve the properties of biodegradable plastics, various types of fillers have been studied which included inorganic fillers (eg: calcium carbonate, nanoclay), natural fibers (both wood and plant fibers) and other types of filler such as carbon nanotubes (Mohanty et al (2000), Andrew and Weisenberge (2015)). 
New applications of AESO based polymers are also desirable because of their availability from renewable resources and biodegradability. In this study, ring-opening polymerization of AESO using glycerol as plasticizer (Luo et al, 2011) is reported. There are two (2) objectives of this research which are to synthesis bioplastics by ring opening polymerization of acrylated epoxidised soybean oil (AESO) with plasticizer and to characterize the properties of AESO bioplastics. The scope of this research was to study the performance of bioplastics developed by mixing of $10 \mathrm{wt} \%$ to $20 \mathrm{wt} \%$ of glycerol in AESO. Characterization of bioplastics was performed using FT-IR analysis, TGA, DSC analysis, XRD analysis and SEM analysis, and to run mechanical testing (tensile strength and Young's modulus) on the synthesized bioplastics.

\subsection{METHODS AND MATERIALS}

Acrylate epoxidised soybean oil (AESO) with 4,000 ppm monomethyl ether hydroquinone as inhibitor was used as the base materials for the synthesis of bioplastics and it was supplied by Sigma-Aldrich Company. Glacial acetic acid (99.85\%) is supplied from Chemmart Asia Sdn. Bhd. The catalyst used in this research is 4dimethylaminopyridine, a derivative of pyridine with the chemical formula (CH3)2NC5H4N and it was supplied by Chemmart Asia Sdn. Glycerol ACS reagent, anhydrous, (99.5\%) is also supplied from Chemmart Asia Sdn. Bhd.

\section{Setup of Synthesis Ring Opening Polymerization}

Different types of equipment were used in the lab for this research work. The ring opening polymerization system consisted of a reactor assembly designed to achieve better mixing and dispersion control of lactic acid and nano fillers into AESO. It includes three neck reaction pot made up of quartz glass, equipped with a dropping funnel, condenser, high stirring motor, thermometer, nitrogen gas supplies and an electro-thermal heater. An additional, opening has been provided on the base of the reaction vessel in order to collect pre-polymer and polymer solutions in due process of experiment. Few other apparatus and equipment are vacuum oven, vacuum pump, oven, temperature and speed controlled mixer, glass wares (beakers, measuring cylinders, and etc), disposable syringes and a fume hood with water. LA and 4-dimethylaminopyridine (DMAP) catalyst are dried under vacuum at $70^{\circ} \mathrm{C}$ for 24 hours, $\mathrm{AESO}$ is dehydrated in a vacuum oven at $60^{\circ} \mathrm{C}$, MMT is dried and dehydrated in vacuum oven at $100{ }^{\circ} \mathrm{C}$ before use.

\section{Sample Preparation}

AESO was dehydrated in a vacuum oven at $60^{\circ} \mathrm{C}$ before use. AESO was mixed with acetic acid $(20 \mathrm{wt} \%)$ and glycerol $(10 \mathrm{wt} \%)$ at around $120^{\circ} \mathrm{C}$ for five $(5)$ hours using mechanical stirrer. The mixture was degassed for five (5) minutes to remove gas bubbles produced in the process. Five (5) $\mathrm{ml}$ of mixture was poured into aluminium weight boat and cured in an oven at $110^{\circ} \mathrm{C}$ for a week to obtain the AESO plastic film. An analogous procedure was used to prepare AESO plastic film containing $15.0 \mathrm{wt} \%$ and $20.0 \mathrm{wt} \%$ glycerol.

\section{Fourier Transform Infrared Spectroscopy (FTIR)}

FTIR analysis was performed using Fourier transform infrared Spectrometer (PerkinElmer: Model 1000 Series) instrument equipped with a universal attenuated total reflectance (UATR) accessory was used to analyze biocomposites and raw materials. The data suggested that spectra were recorded between $4000 \mathrm{~cm}^{-\mathrm{s}}$ and $500 \mathrm{~cm}^{-\mathrm{a}}$ frequency ranges. 


\section{X-Ray Diffraction (XRD)}

XRD measurement was carried out by using a Shimadzu XRD 600 X-ray diffractometer with $\mathrm{CuK} \alpha$ radiation $(\lambda=1.542 \AA)$ operated at $30 \mathrm{kV}$ and $15 \mathrm{~mA}$. Data were collected within the range of scattering angles $(2 \theta)$ of $5^{\circ}$ to $50^{\circ}$ at the rate of $0.02^{\circ} / \mathrm{min}$. The basal spacing was derived from the peak position in the XRD diffractogram according to the Bragg equation $(\lambda=2 \mathrm{~d}$ Sine $\theta)$.

\section{Scanning Electron Microscopy (SEM)}

The surfaces of synthesized bioplastics film were studied under a Hitachi's Tabletop Electron Microscope TM3030Plus at an accelerating voltage of $15 \mathrm{kV}$. SEM was used to identify the molecular structure of the sample to check if the mixtures are well-mixed during the polymerization process.

\section{Thermo gravimetric analysis (TGA)}

Experiments were carried out for performing TGA using a thermal analyzer Mettler Toledo Instruments under a nitrogen atmosphere. Each sample was heated from room temperature to $900^{\circ} \mathrm{C}$ at a rate of $10^{\circ} \mathrm{C} /$ minute in air with a flowrate of in general $50 \mathrm{ml} /$ minute. The weight change of each sample was recorded as a function of temperature. Then mass loss and differential thermal analysis profiles were recorded.

\section{Differential Scanning Calorimetry (DSC)}

DSC analysis was also performed by TA-Instrument DSC/Q 1000 to study the nonisothermal crystallization kinetics. The specimen weight was in general between the ranges of $3 \mathrm{mg}-5 \mathrm{mg}$ and the heating rate employed $10^{\circ} \mathrm{C}$ per minute from $40^{\circ} \mathrm{C}$ to $350^{\circ} \mathrm{C}$.

\section{Tensile Test}

Tensile properties were tested using Shimadzu AG-X series universal testing machine. The samples were cut into dumbbell shapes following ASTM D638 (type V) standard. A load of $5.0 \mathrm{kN}$ was applied at constant crosshead speed of $1 \mathrm{~mm} / \mathrm{min}$ at room temperature. The tensile strength and tensile modulus were evaluated from the force-displacement data. Each sample included three tested replicates to obtain a reliable mean and standard deviation.

\section{Statistical Analysis}

Each batch of samples was prepared with different composition of glycerol. Analysis of variance (ANOVA) was performed by using the Data Analysis tools in Microsoft Excel 2013, and a least significant difference (LSD) test was used to compare the means with a confidence interval of $95 \%$.

\subsection{RESULTS AND DISCUSSION}

The spectrum obtained from the six (6) samples was compared to the existing known materials and identified the material's component and the highest possible matched in each sample is ricinoleic acid ethyl ester.

\section{FTIR Analysis}

The results of FTIR analysis are displayed in Figure 1. The spectrum of cluster peaks below $3000 \mathrm{~cm}^{-1}$ down to around $2850 \mathrm{~cm}^{-1}$ are the peaks from the stretching of sp3hybridised C-H bonds. 
The alcohol O-H group peak is around or about $3300 \mathrm{~cm}^{-1}$. A sharp peak right around $1700 \mathrm{~cm}^{-1}$ could possibly mean that there is a carboxylic acids group in the mixture (Key, 2015)

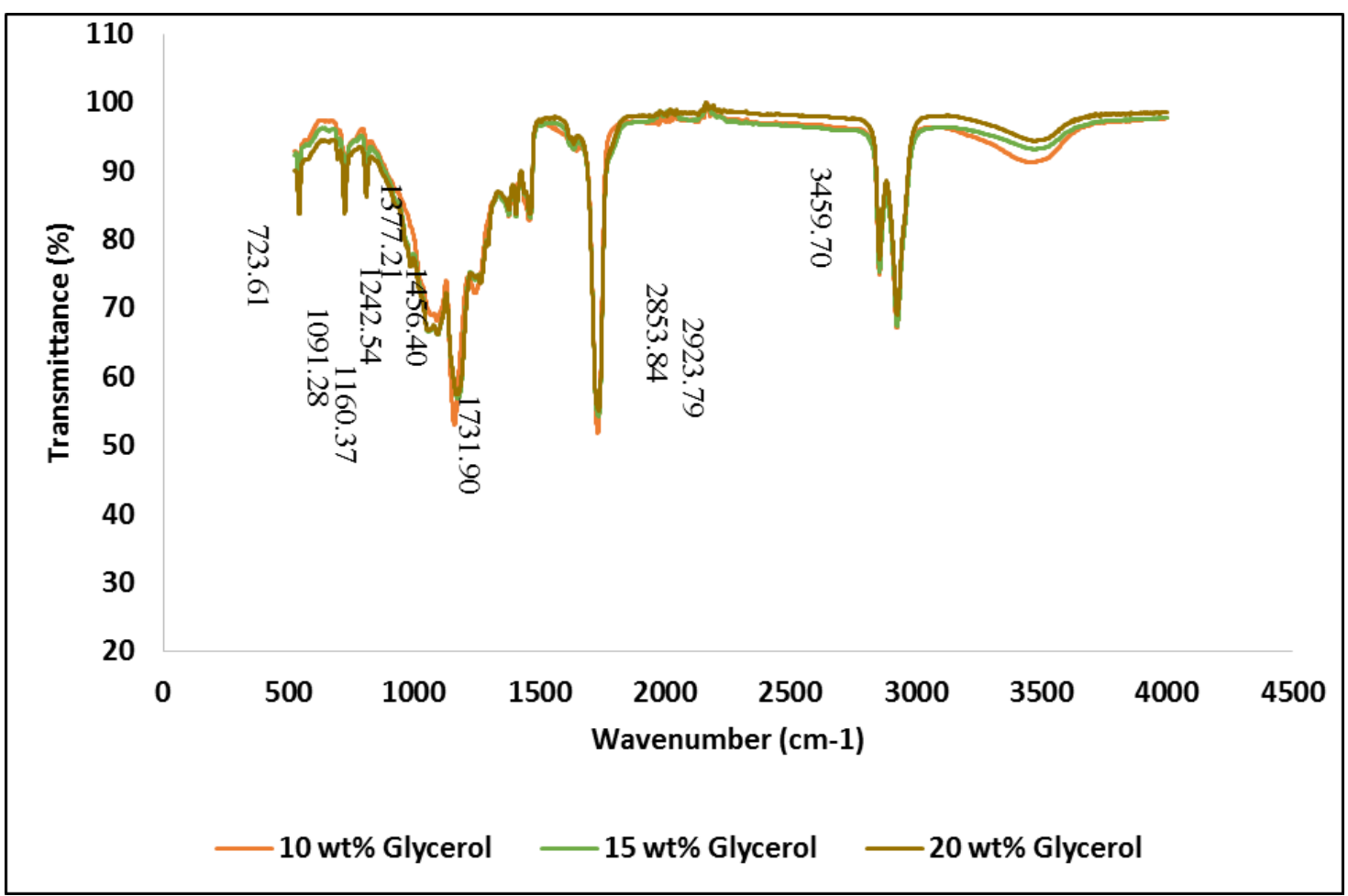

Figure 1: FT-IR graph of AESO-based bioplastics

The criteria of the peaks meet the criteria of the existence of an ester group, which are carbonyl peak around $1740 \mathrm{~cm}-1$, alky peaks below $3000 \mathrm{~cm}-1$ and a very strong peak around $1200 \mathrm{~cm}-1$ for esters which representing the C-O single bond vibration (Wang et al, 2008).

\section{XRD Analysis}

Figure 2, shows the graph of comparison of XRD analysis with different concentrations of glycerol. The graph demonstrates peaks which indicate the strong crystalline characteristics. The shift to higher angle indicates a decrease in the corresponding interlayer spacing, which means that the blend component have an ordered structure. The increase of d-spacing shows that this blend has a less ordered structure, thus crystallization becomes more difficult (Chieng et al, 2014). 


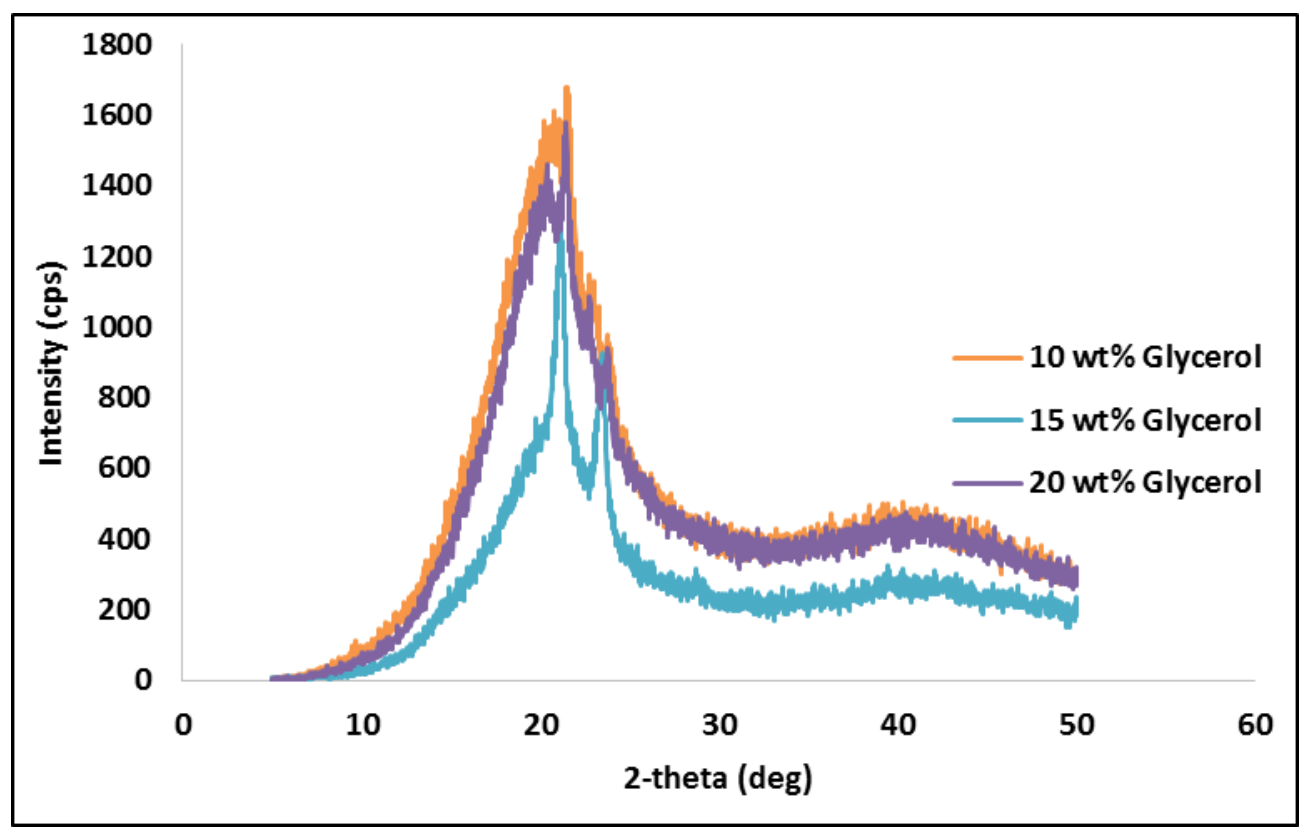

Figure 2: XRD Graph of AESO-based Bioplastics

\section{SEM Analysis}

Figure 3A shows the images of SEM analysis of $10 \mathrm{wt} \%$ of glycerol, Figure 3B shows the SEM images at $15 \mathrm{wt} \%$ of glycerol and Figure 3C shows the SEM images at $20 \mathrm{wt}$ $\%$ of glycerol. Figure $3 \mathrm{~A}$ shows very good compatible morphologies without edge, cavity and holes. This phenomenon shows a good adhesion between the components with a diffused polymer-plasticizer interface, which is attributed to the occurrence of chemical interactions between AESO, glycerol and acetic acid (Fenollar 2009) . Thus, the glycerol was well-dispersed to form a homogeneous matrix with evident signs of plasticization in the AESO matrix, without separation at the interface producing single phase morphology (Silverajah et al, 2012). 

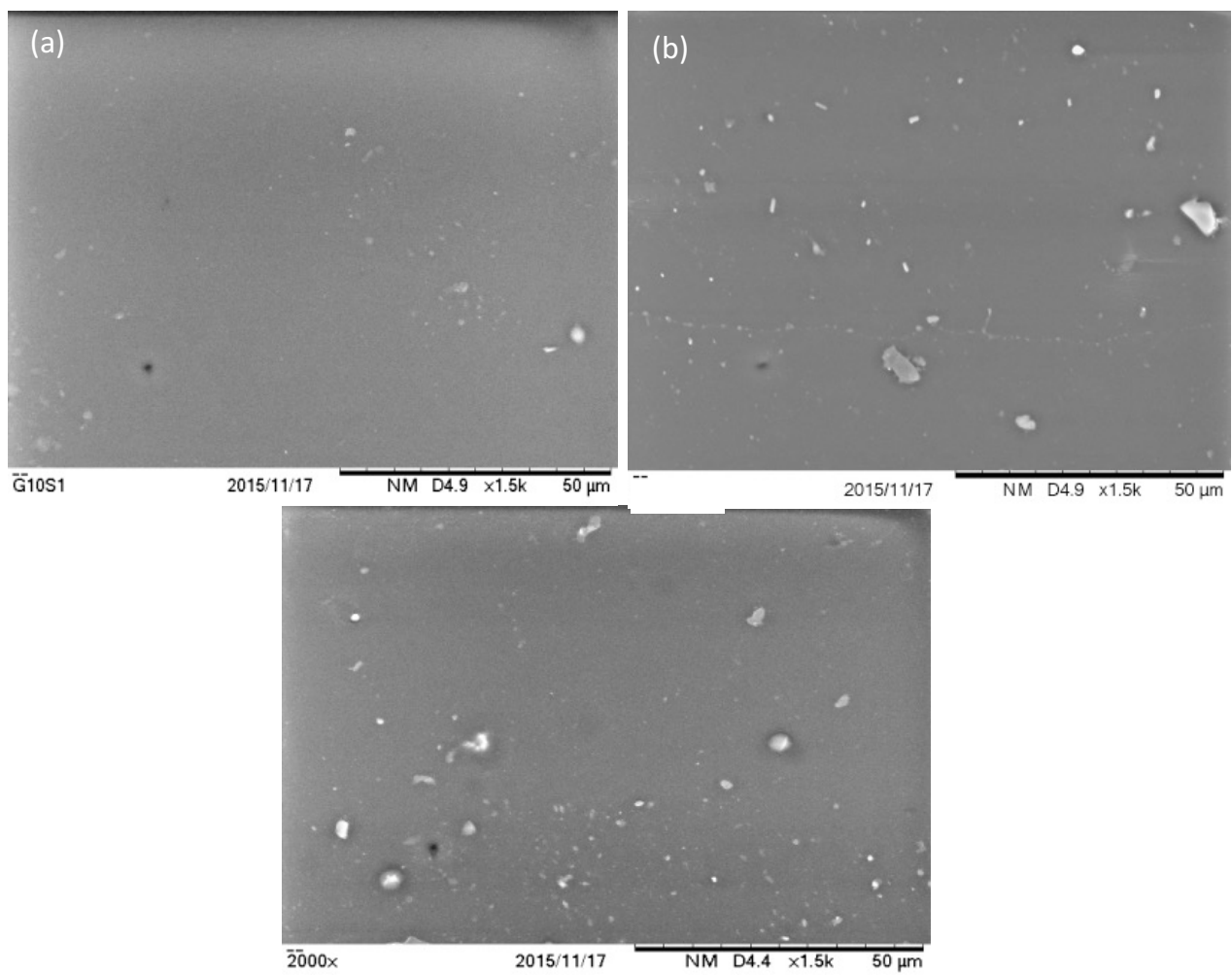

Figure 3: SEM graphs of (A) $10 \mathrm{wt} \%$ glycerol AESO bioplastics film; (B) $15 \mathrm{wt} \%$ glycerol AESO bioplastics film; (C) $20 \mathrm{wt} \%$ glycerol AESO bioplastics film.

On the other hand, SEM analysis on $15 \mathrm{wt} \%$ glycerol AESO plastics films (Figure 3B) and $20 \mathrm{wt} \%$ glycerol AESO plastics films (Figure 3C) show undissolved particles and presence of microvoid. As compared to $15 \mathrm{wt} \%$ glycerol AESO plastics films (Figure 3B), $20 \mathrm{wt} \%$ glycerol AESO plastics films (Figure 3C) shows more voids and undissolved particles. Presence of empty microvoids may due to the degree of dispersion of the plasticizer in the polymer matrix is better at lower plasticizer content, the tendency to form empty voids and phase separation increases when the glycerol content increases (Sanyang et al, 2015).

\section{TGA Analysis}

Figure 4, shows the graph of weigh percentage across room temperature to $900^{\circ} \mathrm{C}$ obtained through TGA analysis. From Figure 4, it can be seen that the AESO bioplastics with different glycerol concentrations have the same trend of weight loss. These Tonset shown in Figure 4 are identical to the research finding where the degradation occurred around $360^{\circ} \mathrm{C}$. Besides, Derivative Thermograms (DTG) was also plotted and shown in Figure 5. From Figure 5, it is shown that the maximum rate of oxidation happens at around $400^{\circ} \mathrm{C}$. 


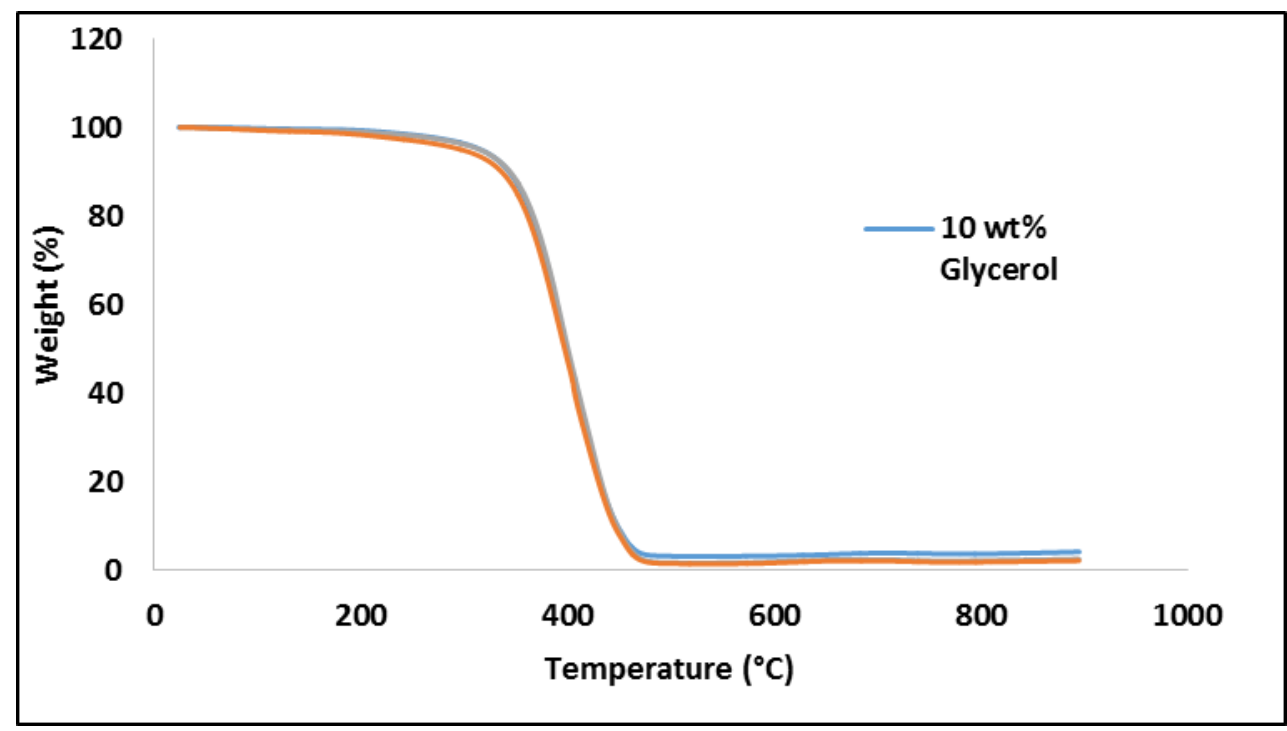

Figure 4: TGA curves of different concentrations of glycerol

Pure Poly-Lactic Acid (PLA) plastics has Tonset of $274.26^{\circ} \mathrm{C}$, with $5 \mathrm{wt} \%$ of epoxidised palm oil is $313.54^{\circ} \mathrm{C}$, and with $2 \mathrm{wt} \%$ of epoxidised Soybean oil is $330.40^{\circ} \mathrm{C}$ (Fenollar et al, 2009). A different study shows that starch-based films have three (3) thermal degradation events where the initial stage started at temperature less than $100^{\circ} \mathrm{C}$, the second stage happened $\sim 125^{\circ} \mathrm{C}$ to $290^{\circ} \mathrm{C}$ and the third staged happened at heating beyond $290^{\circ} \mathrm{C}$ with the Tonset occurred around $300^{\circ} \mathrm{C}$ (Mulla, 2011).

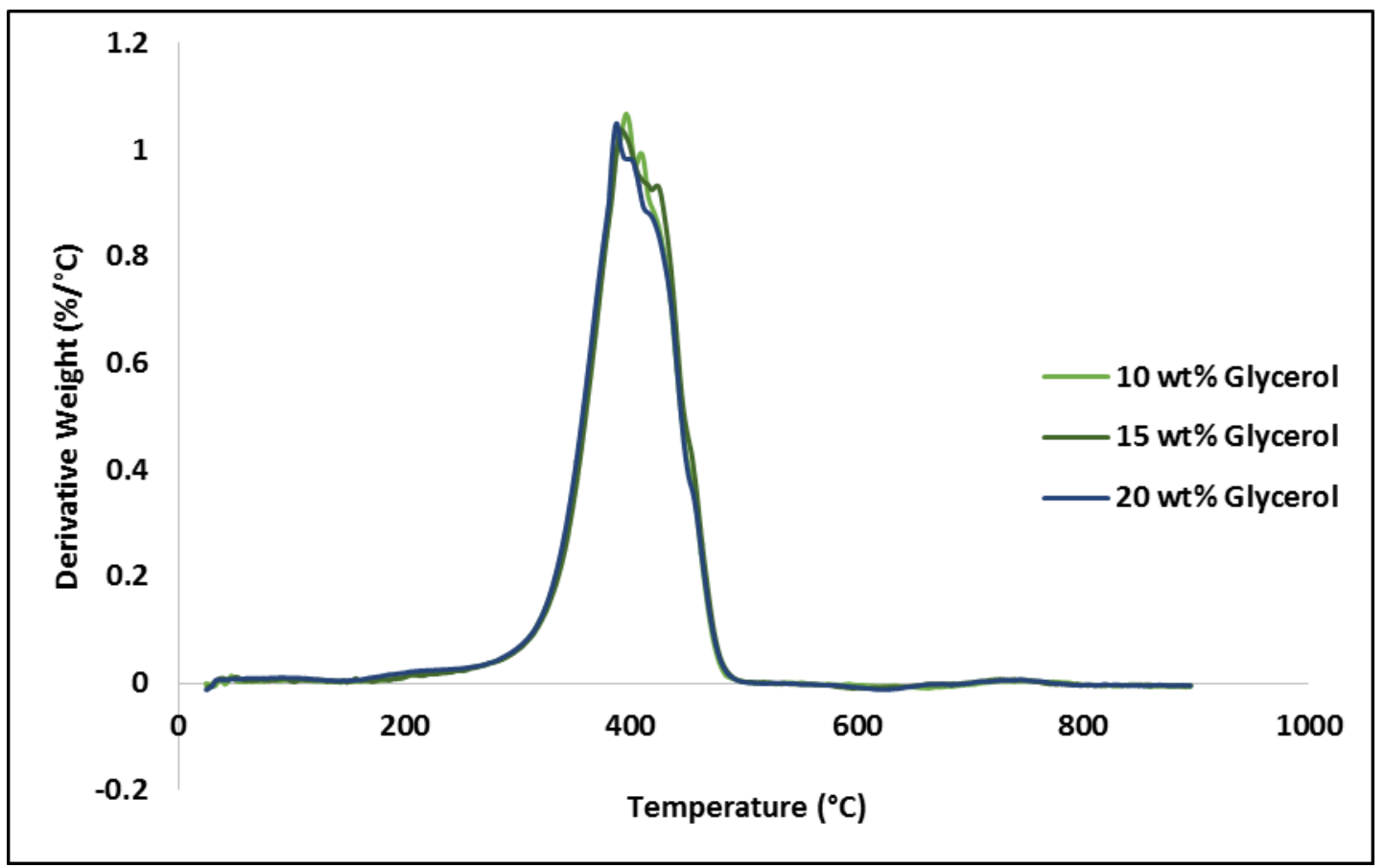

Figure 5: Derivative Thermograms (DTG) of different glycerol concentrations

Therefore, as compared to other biodegradable plastics, AESO bioplastics with glycerol as plasticizer have better thermal stabilities. The AESO bioplastics were observed thermally stable at temperature below $350^{\circ} \mathrm{C}$. Theses higher degradation temperature as 
compared to other biodegradable plastics may due to the increase molecular weight of interaction between AESO and glycerol or AESO matrix itself. Besides, the presence of glycerol which are small molecules that dispersed homogeneously in the PLA polymer acts as a barrier sheet to prevent oxidation, prevent the permeability of volatile degradation out from the blend materials and helps delay the thermal degradation process (Yang et al, 2015). It was reported in a study that the increase of glycerol concentration significantly increase the thermal degradation rate at constant temperature (Mulla, 2011). However, in the present study, increase glycerol concentration has an insignificant effect on the thermal stability. Thermal degradation rate as well as thermal stability which was found similar to the this study (Zhang et al, 2014). This study reported that TGA curves trend similar regardless of the composition of other components.

\section{DSC Analysis}

The thermal properties of AESO bioplastics with different concentrations of glycerol were studies by DSC in range from room temperature to $350^{\circ} \mathrm{C}$ as shown in Figure 6.

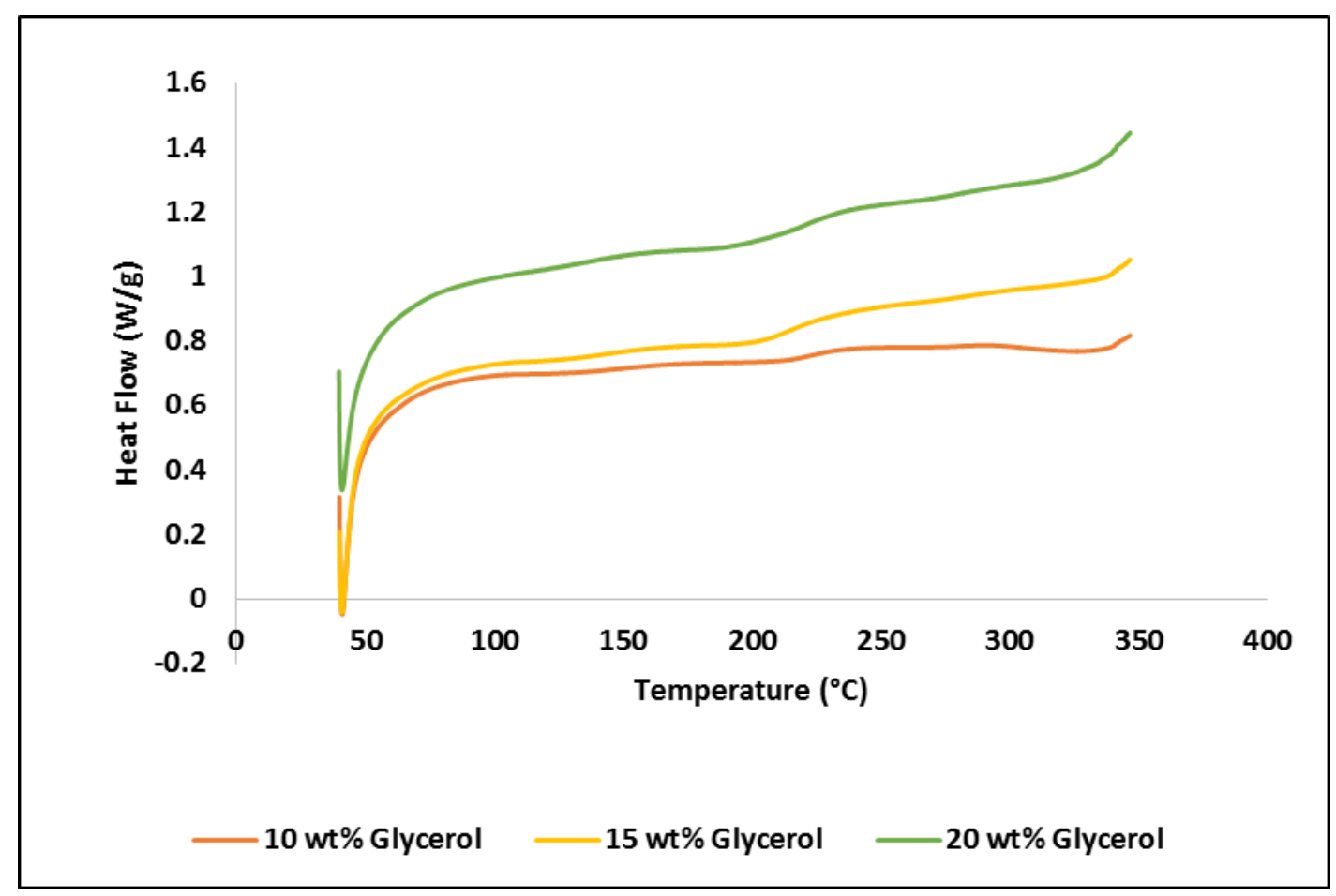

Figure 6: DSC analysis for different glycerol concentrations

The DSC curves show that the melting temperature is around $41^{\circ} \mathrm{C}$. Scala and Wool (2005), reported that glass transition temperature, $\mathrm{Tg}$ of triglycerides with acrylate functionality (AESO, for example) increases approximately linearly $\left(-50\right.$ to $92^{\circ} \mathrm{C}$ ) with cross-linking density induced thermally. The Tg of different glycerol concentration is around $40^{\circ} \mathrm{C}$ which is identical to the pure AESO composite at $40.50^{\circ} \mathrm{C}$ (Yang et al, 2015). By definition, Tg is the temperature at which the forces binding the molecules in the matrix are relaxed to allow large-scale molecular movement (Wittaya, 2013). The addition of plasticizer into the plastic film reduces the Tg, but in (Mulla, 2011) the decrease of $\mathrm{Tg}$ values are 
insignificant when the plasticizer concentrations increases which is similar to the current study.

\section{Tensile Tests}

\section{Tensile strength}

Figure 7, shows the graph of tensile strength versus concentration of glycerol. Pure AESO has a tensile strength of $4.90 \mathrm{MPa}$ it is shown that with the increases of concentration of plasticizer, the tensile strength decreases. Tensile strength of $15 \mathrm{wt} \%$ of glycerol and 20 $\mathrm{wt} \%$ has insignificant difference (Suyatma, 2005). As compared to starch-based bioplastics, AESO bioplastics have relatively lower tensile strength which the tensile strength value of $15 \mathrm{wt} \%$ of glycerol-plasticized sugar palm starch film is $9.59 \mathrm{MPa}$ while AESO film is just $0.898 \mathrm{MPa}$.

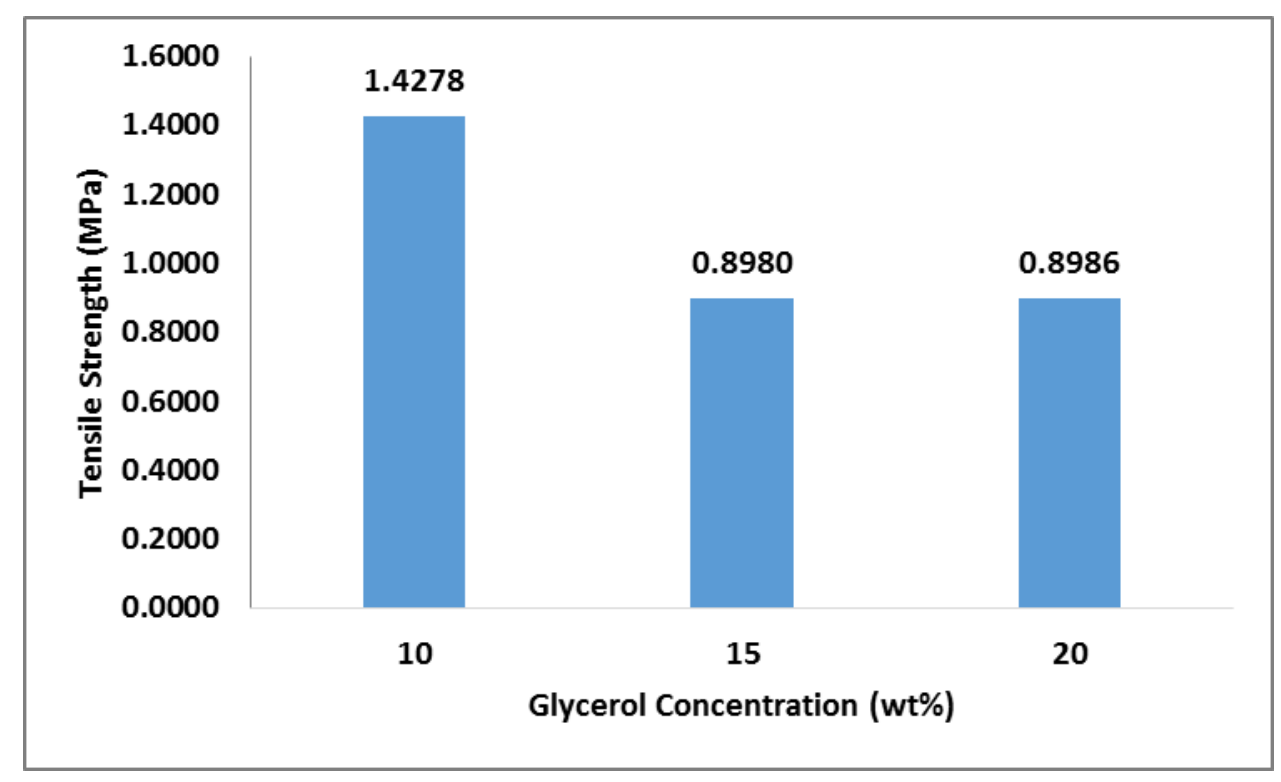

Figure 7: Graph of tensile strength of different concentrations of glycerol

When compared to epoxidized soybean oil-plasticized PLA films, PLA films have much higher tensile strength of $32 \mathrm{MPa}$. Tensile strengths of AESO-based plastics films generally have a lower tensile strength values as compared to other biodegradable plastics such as starch-based and PLA-based plastics film.

\section{Young's Modulus}

Figure 8, shows the graph of Young's modulus versus concentration of glycerol. It is shown that with the increases of glycerol concentration, the Young's modulus decreases. Tensile strength of $15 \mathrm{wt} \%$ of glycerol and $20 \mathrm{wt} \%$ has insignificant difference. As compared to starch-based bioplastics, AESO bioplastics have relatively lower tensile strength which the tensile strength value of $15 \mathrm{wt} \%$ of glycerol-plasticized sugar palm starch film is $9.59 \mathrm{MPa}$ while AESO film is just $0.898 \mathrm{MPa}$. When compared to epoxidized Soybean oil-plasticized PLA films, PLA films have much higher tensile strength of $841 \mathrm{MPa}$. The effect of plasticizer concentration on the Young's modulus was 
observed. Young's modulus of the bioplastic decreased with $15 \%$ glycerol concentration compared to $10 \%$ glycerol concentration. However it increased with the $20 \%$ glycerol concentration, this was found similar to the graph of elongation at break with glycerolplasticized starch plastics. Young's modulus is the function of stress and strain where strain is the function of elongation at break, therefore it is validated that the Young's modulus has an inverse behavior. Young's modulus of AESO-based plastics films generally has a lower Young's modulus values as compared to other biodegradable plastics such as starch-based and PLA-based plastics film.

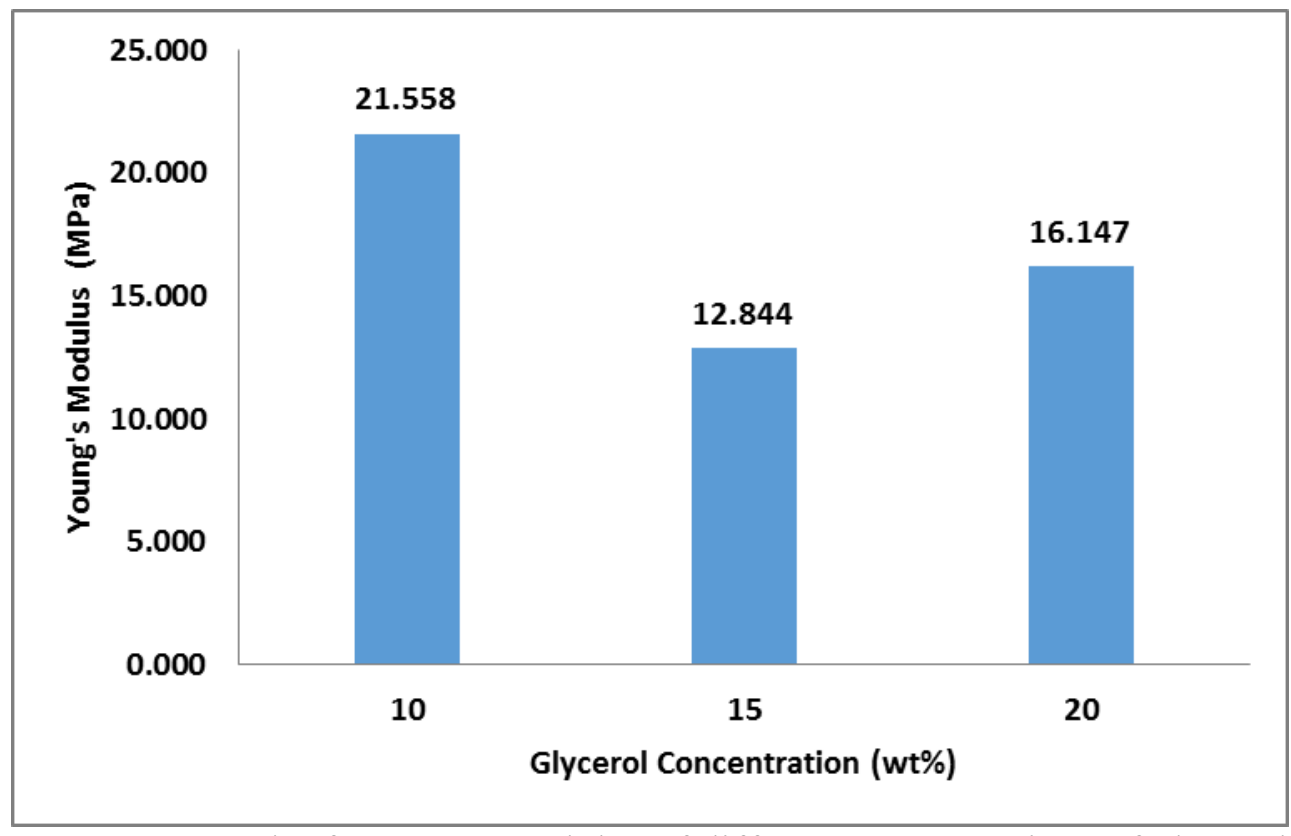

Figure 8: Graph of Young's modulus of different concentrations of glycerol

\subsection{CONCLUSIONS}

Bioplastics were synthesized successfully through ring opening polymerization using acetic acid to form polyols and glycerol as the plasticizer. AESO bioplastics synthesized were made up from ricinoleic acid ethyl ester. Glycerol was found to be compatible with AESO, bioplastics film surfaces were studied using SEM and showed no hole at $5 \mathrm{wt} \%$ glycerol AESO bioplastics. Thermal stability of AESO bioplastics was observed better than other biodegradable plastics. It can be concluded that they were thermally stable below $350^{\circ} \mathrm{C}$ but showed insignificant effect with various compositions of glycerol. This study suggests that tensile strength and Young's modulus values decreased with the increase of glycerol.

\section{ACKNOWLEDGEMENT}

The authors show profound appreciation to Universiti Malaysia Pahang for providing financial assistance in this project through "Internal Grant" funding (RDU140393). 


\section{REFERENCES}

Andrews, R., \& Weisenberger, M. (2015). Carbon Nanotube Polymer Composite. Current Opinion in Solid State And Materials Science, 8(1), 31-37.

Al-Mulla, E., Suhail, A., \& Aowda, S. (2011). New biopolymer nanocomposites based on Epoxidized Soybean Oil Plasticized Poly(Lactic Acid)/Fatty Nitrogen Compounds Modified Clay: Preparation and Characterization. Industrial Crops and Products, 33(1), 23-29.

Ashori, A.,(2008). Wood-plastic composites as promising green-composites for automotive industries! Bioresour Technol. 2008 Jul;99(11):4661-7.

Browne, M. W. (1993, Tuesday, May 25, 1993). With Ivory in Short Supply, Pianists Tickle the Polymers. New York Times.

Chieng, B., Ibrahim, N., Then, Y., \& Loo, Y. (2014). Epoxidized Vegetable Oils Plasticized Poly(lactic acid) Biocomposites: Mechanical, Thermal and Morphology Properties. Molecules, 19(10), 16024-16038.

Clemons, C ( 2002). Source: Forest products journal. Vol. 52, no. 6 (June 2002): Pages $10-18$.

Fenollar, O., García, D., Sánchez, L., López, J., \& Balart, R. (2009). Optimization of the curing conditions of PVC plastisols based on the use of an epoxidized fatty acid ester plasticizer. European Polymer Journal, 45(9), 2674-2684.

Gandini, A., (2008) Polymers from renewable resources: a challenge for the future of macromolecular materials Macromolecules 41 9491-504.

Gunstone, F. (1996). Fatty acid and lipid chemistry. Choice Reviews Online, 34(02), 340934-34-0934.

Harward Key,. (2015). Interpreting Infrared Spectra Painlessly, Quickly, and Correctly. Retrieved 10 December 2015

Hopewell J, Dvorak R, Kosior E. Plastics recycling: challenges and opportunities. Philos Trans R Soc Lond B Biol Sci. 2009 Jul 27;364(1526):2115-26.

Islam, M.R., Beg, M.D., and S. S. Jamari (2014), J. Appl. Polym. Sci., 131, 40787 .(2014)

Islam, M. R., Gupta, A., Rivai, M., Beg, M.D., and Mina, M., (2016). Effects of fibersurface treatment on the properties of hybrid composites prepared from oil palm empty fruit bunch fibers, glass fibers, and recycled polypropylene. , J. Appl. ,Polym. Sci., 133

Khot, S., Lascala, J., Can, E., Morye, S., Williams, G., \& Palmese, G. et al. (2001). Development and application of triglyceride-based polymers and composites. Journal Of Applied Polymer Science, 82(3), 703-723.

Kiatsimkul, P., Suppes, G., Hsieh, F., Lozada, Z., \& Tu, Y. (2008). Preparation of high hydroxyl equivalent weight polyols from vegetable oils. Industrial Crops And Products, 27(3), 257-264.

Kim, J.R., and Sharma, S.,(2012). Ind. Crop. Prod., 36, 485-99 (2012).

Luo, Q., Liu, M., Xu, Y., Ionescu, M., \& Petrović, Z. (2011). Thermosetting Allyl Resins Derived from Soybean Oil. Macromolecules, 44(18), 7149-7157.

Mohanty, A., Misra, M., \& Hinrichsen, G. (2000). Biofibres, biodegradable polymers and biocomposites: An overview. Macromolecular Materials And Engineering, 276277(1), 1-24. 
Mohanty, A.K., Misra, M., and Drzal, L. T. J (2002).Sustainable Bio-Composites from Renewable Resources: Opportunities and Challenges in the Green Materials World Polym. Environ., 10, 19-26 (2002).

Muniyappa, P.R., Brammer, S.C. and Noureddini, H. (1996) "Improved Conversion of Plant Oils and Animal Fats into Biodiesel and Co-Product,".Bioresource Technology, 56, 19-24.

Murray, M. (2007). Green Plastics: An Introduction to the New Science of Biodegradable Plastics E.S. Stevens . Green Plastics: An Introduction to the New Science of Biodegradable Plastics. Princeton University Press. NJ. 238 cloth. 2002. ISBN: 0691-04967-X. Natural Areas Journal, 27(3), 283-285

Piringer,O.G and Baner A.L (2008), "Plastic packaging materials for food: barrier function, mass transport, quality assurance, and legislation”, Wiley, New York.

Raheem D, Application of plastics and paper as food packaging materials - an overview. Emir J Food Agric 25:177-188 (2012).

Raquez, J., Deléglise, M., Lacrampe, M., \& Krawczak, P. (2010). Thermosetting (bio)materials derived from renewable resources: A critical review. Progress In Polymer Science, 35(4), 487-509.

Rivai, M., Gupta,A., Islam, M. R and Beg, M.D (2014) Characterization of Oil Palm Empty Fruit Bunch and Glass Fibre Reinforced Recycled Polypropylene Hybrid Composites Fiber. Polym., 15, 1523-30 (2014).

Sanyang, M., Sapuan, S., Jawaid, M., Ishak, M., \& Sahari, J. (2015). Effect of Plasticizer Type and Concentration on Tensile, Thermal and Barrier Properties of Biodegradable Films Based on Sugar Palm (Arenga Pinnata) Starch. Polymers, 7(6), 1106-1124.

Silverajah, V., Ibrahim, N., Yunus, W., Hassan, H., \& Woei, C. (2012). A Comparative Study on the Mechanical, Thermal and Morphological Characterization of Poly(lactic acid)/Epoxidized Palm Oil Blend. IJMS, 13(12), 5878-5898.

Suyatma, N., Tighzert, L., Copinet, A., \& Coma, V. (2005). Effects of Hydrophilic Plasticizers on Mechanical, Thermal, and Surface Properties of Chitosan Films. J. Agric. Food Chem., 53(10), 3950-3957.

Wang, H., Rong, M., Zhang, M., Hu, J., Chen, H., \& Czigány, T. (2008). Biodegradable Foam Plastics Based on Castor Oil. Biomacromolecules, 9(2), 615-623.

Wittaya, T. (2013). Influence of Type and Concentration of Plasticizers on the Properties of Edible Film From Mung Bean Proteins. KMITL Science And Technology Journal, 13(1), 51-58.

Yang, X., Li, S., Xia, J., Song, J., Huang, K., \& Li, M. (2015). Renewable Myrcene-based UV-curable Monomer and its Copolymers with Acrylated Epoxidized Soybean Oil: Design, Preparation, and Characterization. Bioresources, 10(2).

Zhang, Y., Rempel, C., \& Liu, Q. (2014). Thermoplastic Starch Processing and Characteristics-A Review. Critical Reviews In Food Science And Nutrition, 54(10), 1353-1370. 